\title{
Tuberculous Axillary Lymphadenopathy: A Case Report
}

Nwagbara VI', Maurice E Asuquo ${ }^{1 *}$, Samuel Akpan', ljeoma E Nwachukwu', Martin Nnoli and Theophilus Ugbem ${ }^{2}$

${ }^{1}$ Department of Surgery, University of Calabar Teaching Hospital, Calabar, Nigeria

${ }^{2}$ Department of Pathology, University of Calabar Teaching Hospital, Calabar, Nigeria

\begin{abstract}
Isolated axillary tuberculous lymphadenopathy is rare and described in patients without evidence of previous or ongoing tuberculosis anywhere in the body. Presented is a 26-year-old female with one-year history of axillary swelling, clinical examination and investigations revealed no evidence of tuberculosis elsewhere. Diagnosis was by histology. Tuberculosis should be considered in patients residing in endemic areas with axillary lympha denopathy.
\end{abstract}

Keywords: Isolated; Axillary lymphadenopathy; Tuberculosis

\section{Introduction}

Tuberculosis (TB) is responsible for a high burden of disease and estimated to affect one third of the world population with most in developing countries [1]. Extra pulmonary TB accounts for about $7-30 \%$ of TB cases and lymphadenitis accounts for $17-43 \%$ of cases. Cervical lymph nodes constitute the most common site of involvement with axillary nodes affected in $3.8-20.3 \%$ of tuberculous lymphadenitis $[1,2]$. Isolated axillary tuberculous lymphadenitis is rare and described in patients without previous or active pulmonary $\mathrm{TB}$ and no evidence of the origin of TB detected elsewhere $[3,4]$. Tuberculous lymphadenitis presents as a painless, slowly progressive swelling of a single group of nodes and in $85 \%$ of cases involvement is unilateral [5]. It may resemble breast carcinoma or exist both at the same time resulting in diagnostic and therapeutic challenges $[1,6]$. Confirmation of diagnosis is by histology [4]. We present this case of a primary axillary tuberculous lymphadenopathy in a healthy 26-year-old seronegative female with no evidence of previous or active pulmonary $\mathrm{TB}$ and no evidence of $\mathrm{TB}$ detected elsewhere in the body.

\section{Case Report}

A case report of a 26-year-old female who presented in the outpatient clinic with a history of swelling in the left axilla of one-year duration. The swelling gradually increased in size and was painless. There was a history of occasional low-grade fever but no cough, anorexia or drenching night sweats; no breast changes or left upper limb lesions. Examination revealed a female in good health, two discrete left axillary swellings that measured $3 \times 4 \mathrm{~cm}$ in diameter, mildly tender, firm, smooth surfaced, rubbery and mobile; the contra lateral axilla was unremarkable, breasts, upper limbs and other regions were essentially normal.

Investigations carried out included complete blood count, hemoglobin $12 \mathrm{~g} / \mathrm{dl}$, White blood cell, $5.8 \times 10^{3}$ ul: Lymphocytes $38.1 \%$, monocytes $9.9 \%$, granulocytes $52 \%$. Chest X-ray showed clear lung fields; human immunodeficiency virus I \& II screening negative; fine needle aspiration and cytology of the axillary swelling was indeterminate.

She had left axillary lymph node biopsy; macroscopy showed, 3 lymph nodes with two matted together, the largest node measured $4.5 \times 3 \times 1.5 \mathrm{~cm}$ partly bisected, the cut surfaces were grayish with numerous creamy areas (Figure 1). Microscopy showed lymph node with numerous granuloma with both foreign body and Langhans giant cells. There were extensive areas of caseous necrosis with residual lymphoid tissue, chronic granulomatous inflammation consistent with tuberculosis (Figure 2a and 2b).

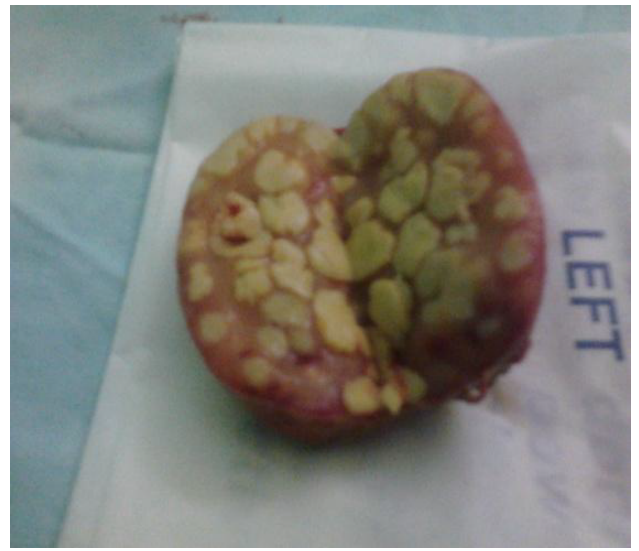

Figure 1: Left axillary lymph node.

Diagnosis was Left axillary tuberculous lymphadenopathy. She commenced anti-tuberculosis chemotherapy with satisfactory therapeutic response. Four months post chemotherapy the left axilla was normal.

\section{Discussion}

Increase in extra pulmonary $\mathrm{TB}$ had been reported in recent years including the subset of lymphadenopathy in non- human immunodeficiency virus (HIV) patients in keeping with this rare report of an isolated axillary lymphadenopathy [2,5]. Despite the new component introduced to the epidemiology of TB with the advent of HIV infection with extra pulmonary TB including lymphadenopathy TB being more common, tuberculous lymphadenopathy in HIV seronegative patients continue to be described and may indicate poor control measures with adverse impact on disease control [2].

Axillary tuberculous lymphadenopathy is rare, presents a problem

*Corresponding author: Maurice E Asuquo, Department of Surgery, University of Calabar Teaching Hospital, Calabar, Nigeria, E-mail: mauefas@yahoo.com

Received July 20, 2013; Accepted August 14, 2013; Published August 17, 2013

Citation: Nwagbara VI, Asuquo ME, Akpan S, Nwachukwu IE, Nnoli M (2013) Tuberculous Axillary Lymphadenopathy: A Case Report. J Trop Dis 1: 113. doi:10.4172/2329-891X.1000113

Copyright: $\odot 2013$ Nwagbara VI, et al. This is an open-access article distributed under the terms of the Creative Commons Attribution License, which permits unrestricted use, distribution, and reproduction in any medium, provided the original author and source are credited. 


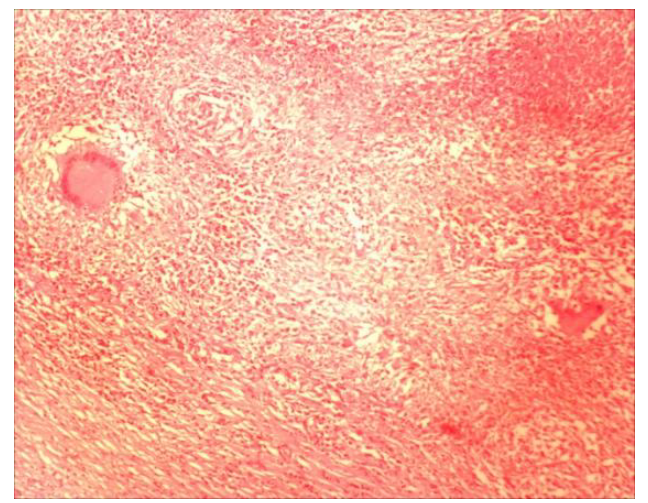

Figure 2a: Chronic granulomatous inflammation, consistent with tuberculosis H\&E $x 40$.

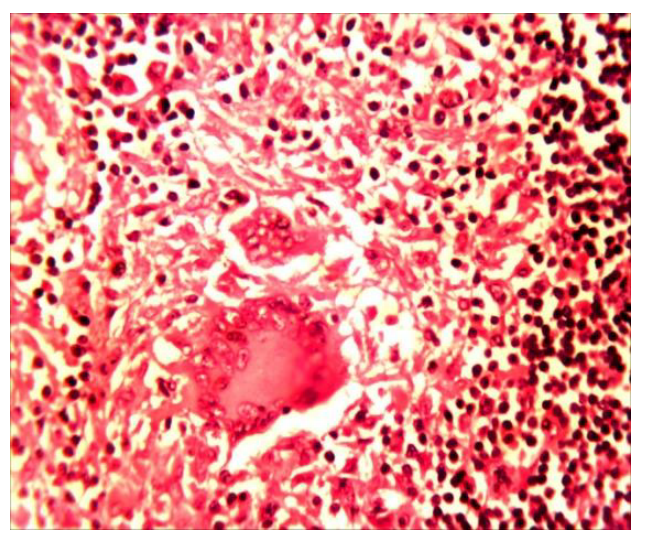

Figure 2b: Chronic granulomatous inflammation, consistent with tuberculosis. H\&E x100.

of differential diagnosis with breast carcinoma, and has a major prevalence between 20-50 years old, which was in keeping with our patient aged 26 years $[7,8]$. The major diagnostic challenge on clinical evaluation was that she had no history of constitutional symptoms of $\mathrm{TB}$ and no breast lesion on examination. The initial thought was that of a lymphadenopathy possibly from an occult breast carcinoma. The breast can be a primary site of TB but more commonly secondary that spreads to the breast through the lymphatic system from the axilla [4]. Our patient may have presented prior to this stage of development. The occurrence of TB with carcinoma is unusual but reported to coexist in axillary lymph nodes without pulmonary or mammary TB [9].

In a situation of diagnostic dilemma, the presence of calcifications on radiography should raise the possibility of TB even in the absence of exposure to TB [10]. Fugii et al reported that $\mathrm{x}$-ray is useful for a diagnosis of lymph node TB and should be suspected with the appearance of clustered calcifications in axillary lymph nodes [11]. This was not our experience as our patient may have presented prior to this stage of calcification. Confirmation of diagnosis is by histology in keeping with our experience (Figure $2 \mathrm{a}$ and $2 \mathrm{~b}$ ) [4].

Axillary tuberculosis lymphadenopathy remains a rare condition, and should be considered in patients living in endemic areas of TB.

\section{References}

1. Porto L, Filho IC, Ramalho E, Miranda J, Leal M, et al. Axillary Tuberculous lymphadenitis: a case report and a literature review. Journal of Senologic International Society.

2. Nwagbara VI, Asuquo ME, Ebughe G, Agbor C, Akpan S, et al. (2013) Tuberculous lymphadenitis of the neck: Case series. International Journam of Medicine 1: 4-8.

3. Yang CM, Hsu CH, Hsieh CM, Chen MY (2003) 18 F-FDG-PET in a clinical unsuspected axillary tuberculosis lymphadenitis mimicking malignancy. Ann Nucl Med Sci 16: 107-110.

4. Culpinar K, Erpulat Ozis S, Ozdemir S, Korkmaz A (2013) Primary breast tuberculosis: Report of a case. Surgical Science 4: 68-71.

5. Fontanilla JM, Barnes A, von Reyn CF (2011) Current diagnosis and management of peripheral tuberculous lymphadenitis. Clin Infect Dis 53: 555562.

6. Mohapatra PR, Janmeja AK (2009) Tuberculous lymphadenitis. J Assoc Physicians India 57: 585-590.

7. Bem C, Patil PS, Bharucha H, Namaambo K, Luo N (1996) Importance of human immunodeficiency virus-associated lymphadenopathy and tuberculous lymphadenitis in patients undergoing lymph node biopsy in Zambia. Br J Surg 83: 75-78.

8. Jerbi M, Hidar S, El Moueddeb S, Jemaa A, Korbi S, et al. (2007) [Tuberculous axillary lymphadenitis: an unusual presentation]. Rev Med Liege 62: 188-189.

9. Pandey M, Abraham EK, K C, Rajan B (2003) Tuberculosis and metastatic carcinoma coexistence in axillary lymph node: A case report. World J Surg Oncol 1: 3 .

10. Baslaim MM, Al-Amoudi SA, Al-Ghamdi MA, Ashour AS, Al-Numani TS (2013) Case report: Breast cancer associated with contralateral tuberculosis of axillary lymph nodes. World J Surg Oncol 11: 43.

11. Fujii T, Kimura M, Yanagita $Y$, Koida T, Kuwano $H$ (2003) Tuberculosis of axillary lymph nodes with primary breast cancer. Breast Cancer 10: 175-178. 